\title{
CAPTURAS FLUVIAIS COMO EVIDÊNCIAS DA EVOLUÇÃO DO RELEVO: UMA REVISÃO BIBLIOGRÁFICA
}

Déborah de Oliveira ${ }^{1}$

Resumo: Este estudo apresenta uma síntese dos tipos fundamentais de capturas fluviais, de acordo com sua evolução ou morfogênese. Foi realizado por meio de pesquisa bibliográfica, na qual algumas obras clássicas foram revisitadas e outras, mais atuais, consultadas, além da consideração do estudo de caso pesquisado em OLIVEIRA (2003) e OLIVEIRA e QUEIROZ NETO (2007), para a bacia do rio Guaratuba, na escarpa da Serra do Mar. Captura fluvial (river capture ou stream piracy) corresponde ao desvio natural das águas de uma bacia hidrográfica para outra, promovendo a expansão de uma drenagem em detrimento da vizinha. Sabe-se hoje, de acordo com a pesquisa bibliográfica, que a maior parte dos autores parece concordar que esse processo geomorfológico pode ocorrer por meio da absorção de um rio por outro, do recuo de uma das cabeceiras, do aplanamento lateral geral, do transbordamento de um rio em outro ou do desvio subterrâneo de um rio, até que atinja um rio vizinho. 0 rio capturado muda bruscamente de direção no ponto da captura, local conhecido como cotovelo de captura. O rio que capta é chamado de captador, capturador ou beneficiário; a parte montante do curso captado é chamada de capturada ou decapitada. As capturas fluviais apresentam importantes evidências da mudança do relevo, como a presença de um cotovelo de captura, de vales secos, mortos ou abandonados, com seixos rolados em seu vale e rupturas de declive no perfil longitudinal dos rios.

Palavras-chave: Capturas fluviais; Evolução do relevo; Evidências de captura.

\section{Introdução}

Este estudo apresenta uma síntese dos tipos fundamentais de capturas fluviais reconhecidos até o momento, de acordo com sua evolução ou morfogênese. Foi realizado por meio de pesquisa bibliográfica, na qual algumas obras clássicas foram revisitadas e outras, mais atuais, consultadas, além da consideração do estudo de caso pesquisado em OLIVEIRA (2003) e OLIVEIRA e QUEIROZ NETO (2007), para a bacia do rio Guaratuba, na escarpa da Serra do Mar.

O fenômeno das capturas fluviais foi inicialmente reconhecido no final do século XIX, principalmente por pesquisadores americanos e franceses. Neste período, destaca-se o estudo de caso da captura do rio Mosa pelo rio Mosela, ocorrido na região da Lorena, França (DAVIS, 1896 a, b e c, 1909). Próximo à cidade de Toul, o rio Mosela corria por um vale sinuoso passando pela cidadezinha de Pagny-surMeuse, até que um de seus afluentes desviou o rio Mosa em seu proveito. Entre Toul e Pagny-sur-Meuse formou-se um vale seco, abandonado ou morto. A forma do vale sugere que 0 curso d'água que o ocupava tinha um volume considerável. Nas redondezas de
Toul observa-se um cotovelo de captura bem característico e, no vale abandonado, uma massa de detritos relativamente considerável que desceu do topo das vertentes até o fundo da depressão, obstruiu a passagem dos cursos d'água no vale morto. (Fig. 1). Hoje sabe-se que esta captura fluvial ocorreu por (déversement) transbordamento (TECHER, 1995).

A captura do rio Mosa pelo rio Mosela foi considerada por muito tempo como relativamente recente (final do Pleistoceno médio) devido à boa preservação dos depósitos e da morfologia fluvial. Com a datação de materiais superficiais e subsuperficiais, foi constatado que esta captura é mais antiga do que se imaginava. Ela estaria diretamente relacionada ao sistema de carste da área em questão (LOSSON e QUINIF, 2001, 2004).

A captura fluvial (river capture ou stream piracy) corresponde ao desvio natural das águas de uma bacia hidrográfica para outra, promovendo a expansão de uma drenagem em detrimento da vizinha (CHRISTOFOLETTI, 1975). Um rio comete pirataria (piracy) ao conquistar seu vizinho (MILLER,1915). É um importante processo no desenvolvimento da drenagem, sujeita ou não a controles estruturais

\footnotetext{
${ }_{1}$ Professora Doutora do Departamento de Geografia da Universidade de São Paulo (debolive@usp.br).
} 


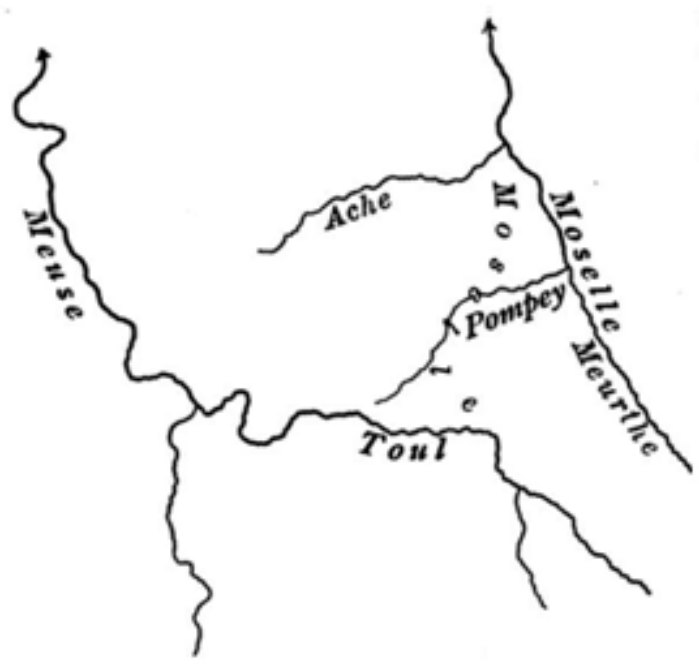

Situação anterior à captura

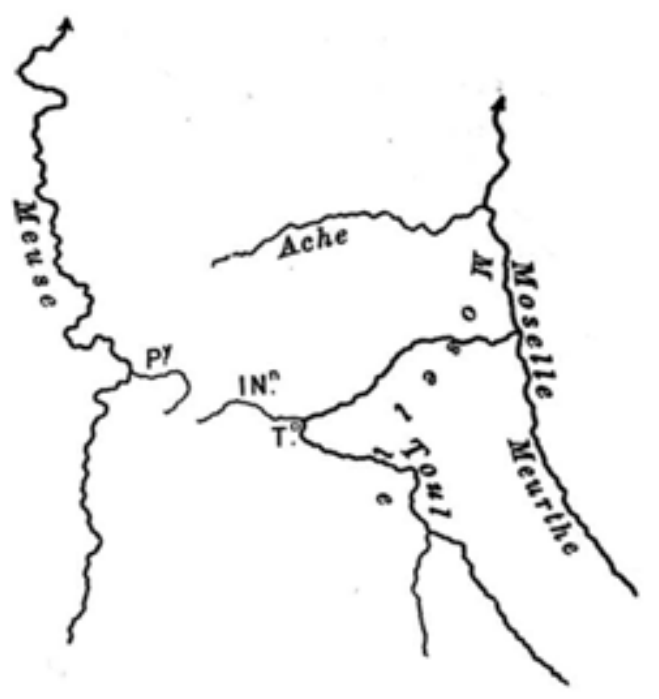

Situação após a captura

Figura 1 Captura Fluvial Mosa-Mosela (Meuse-Moselle).

Fonte: DAVIS (1909)

(SUMMERFIELD, 1991). Tem sido propostos casos de captura fluvial em várias escalas, mas seus mecanismos são controversos. Alguns pesquisadores acreditam que captura fluvial é um evento raro e acontece somente em pequenas escalas, mas todos concordam que a água é o maior acelerador $\mathrm{e}$ o elemento chave das capturas fluviais e que são o resultado de uma sucessão de respostas a eventos climáticos (PEDERSON, 2001). A habilidade de um rio capturar outro depende da sua habilidade de manter seu canal em um nível mais baixo que aquele do rio superior. Assim sendo, os principais fatores que comandam as taxas de erosão mecânica do canal são: o grau de inclinação, a alta energia e a vantagem erosiva, que são também atribuídos como chaves de identificação de uma captura fluvial (BISHOP, 1995).

Espantosamente, os processos de captura fluvial têm recebido pouca atenção por parte dos geomorfológos. Apesar da pequena ressurgência de interesse e a contínua importância do entendimento da história da drenagem e sua interpretação, os precisos processos de rearranjo da drenagem permanecem pobremente elucidados. Os processos de captura fluvial continuam sendo invocados sem nenhuma aparente consideração aos processos pelos quais a captura ocorreu, isto é, sem se levar em conta que a chave para o entendimento da captura fluvial, isto é, as linhas da drenagem, estão preservadas durante e após a captura (BISHOP, 1995).

No início do século XX, as capturas fluviais foram classificadas de acordo com os seguintes estágios de desenvolvimento: captura previsível, captura iminente, captura em vias de execução (notadamente pela trasvasagem das águas subterrâneas), captura recente, captura antiga (demonstrada pela existência de um canal fluvial abandonado, captura sugerida somente pela disposição da rede hidrográfica ou pela distribuição dos aluviões antigos). Naquele momento, acreditava-se que estes tipos de capturas fluviais implicavam a ação preponderante da erosão regressiva, estimulada seja pela diferença dos níveis de base, seja por uma forte diferenciação estrutural ou por um grande contraste climático. Aliás, qualquer que seja a causa, a mudança de um curso aproveita o curso d'água mais ativo, que aparece como um capturador. Mas existem casos onde a erosão regressiva não exerce nenhum papel, como dos rios de mesma altitude. Há outros onde, ao contrário, a mudança do curso resulta de uma colmatagem. Em um caso ou em outro, é o rio mais ativo que se desvia espontaneamente para um rio vizinho, que se beneficia de um acontecimento que ele não provocou. Neste caso, a palavra captura não convém, mas transbordamento 
é o termo mais adequado (déversement) (BAULIG, 1937, 1950).

Até meados do século XX foi elaborada uma sistematização dos casos de capturas fluviais encontrados até aquele momento. Percebeu-se, então, que as capturas fluviais podiam ocorrer tanto superficial como subsuperficialmente. Neste sentido, acreditavase que as capturas fluviais podiam envolver dois rios superficiais, dois rios subterrâneos ou um rio superficial e um rio subsuperficial. Naquele momento foram identificados três tipos de capturas fluviais: por erosão regressiva de uma das cabeceiras (headward erosion), por aplanamento lateral geral (planation capture) e por erosão subterrânea (by underground methods) (CROSBY, 1937). A captura fluvial por erosão regressiva ocorre quando dois rios adjacentes estão em níveis topográficos diferentes e o tributário do rio inferior erode na direção do rio superior, atravessando o divisor de águas e capturando-o. A captura por aplanamento lateral acontece quando um rio corta 0 divisor de águas lateralmente na direção de outro rio e não está necessariamente em níveis diferentes. A captura subterrânea acontece em regiões onde predominam rochas solúveis, onde um rio erode sua cabeceira subsuperficialmente.

A captura fluvial envolve 0 ataque de uma erosão ativa pela drenagem de um rio sobre outro, que resulta no desvio de parte de suas águas para o rio capturador. Atualmente sabe-se que as capturas fluviais podem acontecer por absorção de um rio por outro (abstraction), por recuo de uma das cabeceiras (headward erosion), por aplanamento lateral geral (lateral planation), por desvio subterrâneo de um rio (subterranean diversion) (THORNBURY, 1957; FAIRBRIDGE, 1968; SMALL, 1977) e por transbordamento de um rio (déversement) (CHRISTOFOLETTI, 1975, 1977, 1981).

Quando a captura acontece por absorção, há a captação de águas por determinados rios em detrimento dos adjacentes, devido à competição que se estabelece ao longo de uma superfície, pois alguns rios entalham mais rapidamente do que outros, alargando seus vales, que passam a englobar os cursos laterais. 0 recuo das cabeceiras acontece quando dois rios adjacentes estão localizados em altitudes diferentes e os tributários do curso mais baixo provocam a erosão regressiva de suas cabeceiras, atravessando o interflúvio e capturando o curso d'água localizado em nível topográfico mais alto. A captura pode também resultar de aplanamento lateral, onde o rio principal pode cortar o interflúvio que o separa do tributário e desviar a parte montante do mesmo, deixando seco o vale localizado na parte jusante do curso decapitado. A captura por transbordamento realiza-se quando um curso d'água entulha seu leito por receber muitos sedimentos, elevando-o até um nível superior ao dos colos mais baixos que separam seu vale dos adjacentes. A captura subterrânea ocorre em áreas de rochas calcárias ou em áreas de rochas solúveis, quando um rio erode sua cabeceira subsuperficialmente até alcançar outro rio. (CHRISTOFOLETTI, 1975; 1977; 1981).

Pode-se observar a presença de um conjunto de evidências que confirmam a ocorrência de capturas fluviais, como o que chamamos de cotovelos de captura (elbows of capture), que correspondem a uma mudança brusca no curso de um rio numa curva de $90^{\circ}$ e que são influenciados por fatores geológicos, aos quais o rio ajusta-se e são a maior suspeita de evidência de capturas fluviais; os rios residuais (misfit streams) por redução de sua descarga, os quais foram encarados como a maior evidência de captura fluvial, mas hoje sabemos que podem ser resultado de outras causas, como uma mudança climática envolvendo redução da precipitação e aumento da evapotranspiração e percolação; os colos ou vales mortos, secos ou abandonados (cols or wind-gaps), imediatamente adjacentes ao ponto da captura, sabendo-se que a existência de um colo não é necessariamente uma prova de captura, mas a proveniência dos seixos rolados (fluviatile gravels) existentes em seu vale. $O$ vale seco (wind gap) é apenas um colo no topo do interflúvio cortado pelo recuo da nascente de dois rios, que tem suas nascentes uma em oposição à outra. Neste caso, 0 termo wind gap significa que o rio não ocupa mais seu vale, mas que somente o vento passa por ali (MILLER,1915). Outra evidência é observar o perfil longitudinal do rio (river profile), que ajuda a reconstituir sua história, observando rupturas de declive formadas quando seu nível de base rebaixa-se no lugar onde é capturado por outro rio (SMALL, 1977).

O rio que capta é chamado de captador, capturador ou beneficiário; a parte montante do curso captado é chamada de capturada ou decapitada.

Alguns pesquisadores propõem métodos para se evidenciar as capturas fluviais, como a fotointerpretação, com o estudo cuidadoso dos padrões de drenagem e identificação no campo da fonte dos cascalhos nos vales dos rios, para uma completa análise do padrão da drenagem presente e possíveis sistemas de paleodrenagem (SCHUMM, 1977; WOODRUFF, 1977; CHRISTOFOLETTI, 1981). Outros pesquisadores afirmam que em algumas regiões, a captura fluvial é o fator principal de desenvolvimento de uma paisagem de terraços e que os rios podem ser os responsáveis pela deposição de material grosseiro em seu vale e podem dar pistas sobre a origem destes cascalhos, isto é, sua área fonte, no caso de uma captura fluvial (RITTER, 1972). 
Em alguns casos, os depósitos fluviais devem existir em áreas onde há pequenos rios ou rios não existentes. Terraços também dão excelentes pistas para reconhecer mudanças no fluxo do rio. As inclinações dos depósitos do terraço refletem a direção do fluxo quando os sedimentos foram depositados. Se a direção dos depósitos do terraço for diferente do canal atual, isto pode indicar uma captura fluvial. Se um depósito fluvial contém tipos de rochas não compatíveis com o rio atual, isto pode indicar que uma captura fluvial ocorreu anteriormente (ZAPROWSKI et al., 2002).

As evidências gráficas incluem a configuração das redes de drenagem, a geometria da bacia de drenagem, o diagnóstico das características geológicas que existem nos interflúvios das bacias adjacentes. Deste modo, algumas evidências são encontradas nos interflúvios e não no curso dos rios. Os perfis longitudinais são usados somente para mostrar similaridades na forma geral entre rios ativos e características reliquiais, erosional e deposicional, próximas aos interflúvios (WOODRUFF, 1977).

São importantes também as simulações por computador por modelagem geomorfológica para se reconstituir a drenagem, sobretudo onde o interesse é a neotectônica (CLARK, 1989). Neste sentido, é importante relacionar os produtos da fotointerpretação, os produtos cartográficos digitais elaborados por Sistemas de Informação Geográfica (SIGs) com as evidências encontradas em campo para se reconstituir a história da evolução do relevo onde aconteceu a captura fluvial (OLIVEIRA, 2003; OLIVEIRA e QUEIROZ NETO, 2007).

\section{Exemplos de captura fluvial de acordo com a classificação proposta por CHRISTOFOLETTI (1975)}

\section{Captura fluvial por absorção}

As montanhas Henry estão situadas ao sul do Estado de Utah, nos Estados Unidos da América, à oeste do rio Colorado, entre seus afluentes Fremont e Escalante. É uma região desértica, de grande interesse para a geologia estrutural, onde predominam rochas sedimentares, com intrusões de lacólitos (Fig. 2). A erosão das superfícies expôs os lacólitos, que são mais resistentes do que as camadas sedimentares rompidas, fazendo as vertentes convexas passarem a côncavas, ocasionado a captura de rios paralelos por absorção.

\section{Captura fluvial por recuo das cabeceiras}

A captura fluvial do alto rio Guaratuba foi resultado da erosão regressiva da escarpa da Serra do Mar em Bertioga-SP, que capturou o rio Guaratuba, cujo curso pretérito dirigia-se para a bacia do rio Claro, afluente do rio Tietêe, atualmente, deságua no Oceano Atlântico (Fig. 3). Algumas evidências foram encontradas, como por exemplo: a mudança brusca de direção do rio Guaratuba, que passa de NE-SW para N-S, cortando os alinhamentos, no cotovelo de captura, próximo à escarpa; 0 vale em $\mathrm{V}$ fechado no cotovelo de captura; um vale abandonado pantanoso e cascalhento próximo ao cotovelo de captura e o nível de base local do rio Guaratuba mais baixo do que o do rio Claro no Planalto (OLIVEIRA, 2003; OLIVEIRA e QUEIROZ NETO, 2007) .

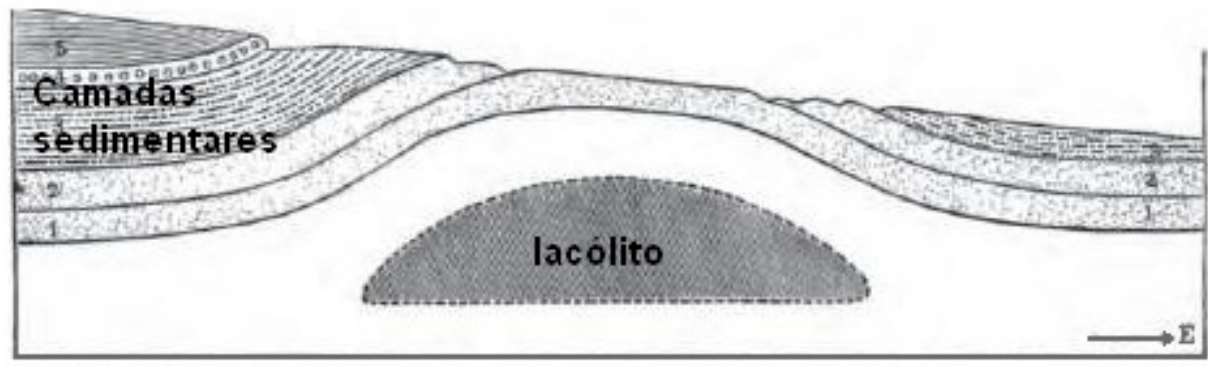

Figura 2 Perfil mostrando o rompimento das camadas sedimentares por intrusão de lacólitos nas montandas Henry, Utah (EUA).

Fonte: GILBERT (1880) 


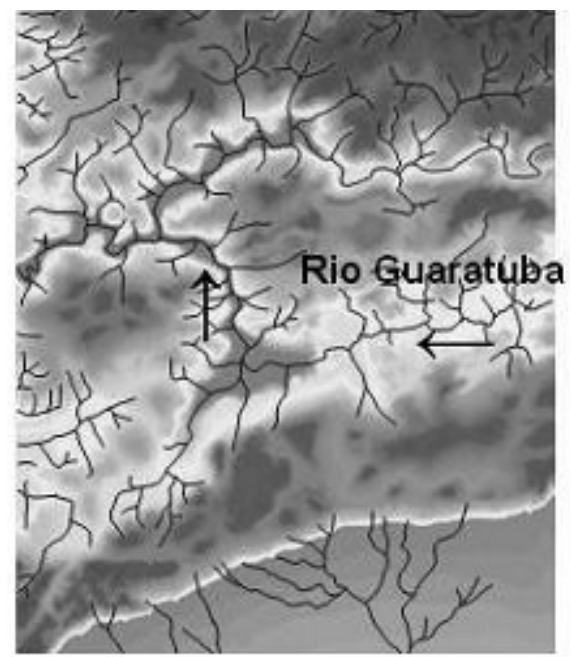

Situaçã̃o anterior à captura

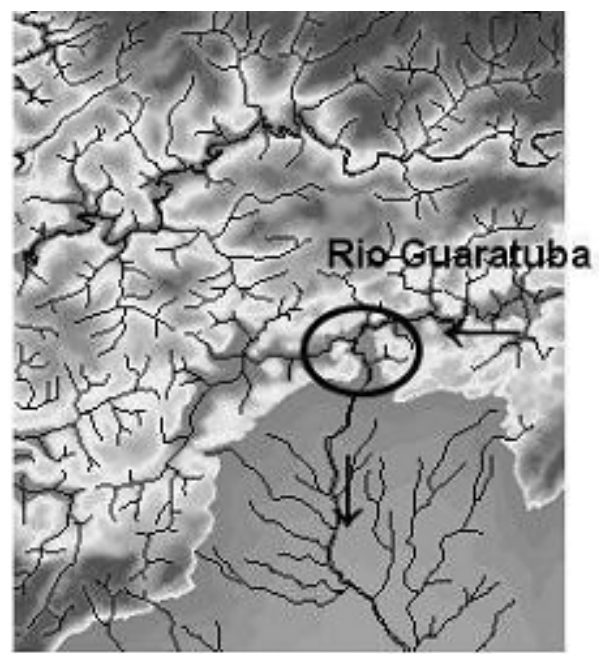

Situaçẫo atual

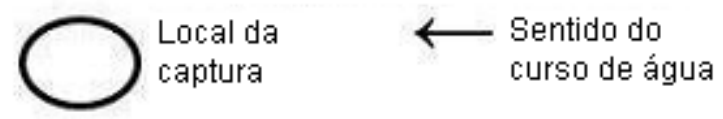

Figura 3 Captura fluvial na Serra do Mar-SP.

Fonte: OLIVEIRA (2003)

\section{Captura fluvial por aplanamento lateral}

A mudança do nível de base e 0 ajuste da rede de drenagem por captura fluvial em Sorbas, SE da Espanha, baseou-se na combinação de evidências de registros geológicos (sedimentos Plio/Pleistocenos) e registros geomorfológicos (alinhamento de drenagem, grau de incisão e colo de captura) para entender a complexa evolução da rede de drenagem, desde a mudança do nível de base (Fig. 4). A litologia da área de estudo e os lineamentos estruturais influenciaram a formação de capturas. O soerguimento da área afetou os gradientes regionais, o que estimulou muitas capturas; as flutuações climáticas estimularam a agradação e degradação nas bacias hidrográficas, dependendo do aumento ou diminuição do suprimento de sedimentos, além da ação humana, que compactando superfícies, removendo a vegetação e aumentando a erosão criou problemas com a estabilidade das vertentes. A mudança de nível de base, combinada com variadas suscetibilidades da geologia, levou a uma reorganização muito complicada da rede de drenagem. 0 produto final dessa complexa reorganização da drenagem é uma série de vales adjacentes, que têm histórias geomorfológicas diferentes. Assim, a suscetibilidade da rede de drenagem varia com as características geológicas da área de estudo: 1) controles estruturais no alinhamento da drenagem; 2) controles litológicos na erodibilidade dos sedimentos, influindo na expansão da rede de drenagem e desenvolvimento de badlands; 3) controles geológicos no desenvolvimento da drenagem de subsuperfície. Onde essa drenagem se desenvolveu houve um contínuo rebaixamento do nível de base e levou à captura do rio Mocátan pelo rio Infiemo e um afluente deste pelo rio Hueli (MATHER, 2000).

\section{Captura fluvial por transbordamento}

A captura do Furnace Creek Wash pelo Gower Gulch no Vale da Morte (Califórnia) aconteceu por transbordamento (Fig. 5).

De oeste para leste existem vários níveis topográficos superpostos: o Vale da Morte a $75 \mathrm{~m}$, as colinas a 120-150 m, o ponto de observação a $220 \mathrm{~m}$, que faz parte de um nível dissecado e a leste os pedimentos a $350 \mathrm{~m}$, que são divididos em: os mais altos, que compreendem os mais antigos e mais recentes e os mais baixos, que compreendem os três glacis reconhecidos na maior parte do Vale da Morte. Os materiais do cone de dejecção que aparecem no Gower Gulch provêm da zona Zabriskie, próxima ao cotovelo de captura. São basaltos alógenos superficiais de $5 \mathrm{a} 10 \mathrm{~cm}$ de espessura, contrastando com os materiais subsuperficiais do Mio-Plioceno. Após a realização da captura, toda a carga sólida do Furnace Creek Wash atinge o Vale da Morte pelo Gower Gulch.

Os responsáveis por essa captura foram os movimentos tectônicos que aumentaram depois da última glaciação e obrigaram a rede hidrográfica a uma readaptação. Tratou-se, conseqüentemente, de uma captura por transbordamento, à medida que se observou uma barragem aluvial de $3 \mathrm{~m}$ que existe próximo ao cotovelo de captura. Essa barragem aluvial é alimentada por um afluente de Furnace Creek, agora tributário do Grower Gulch (POUQUET, 1964). 

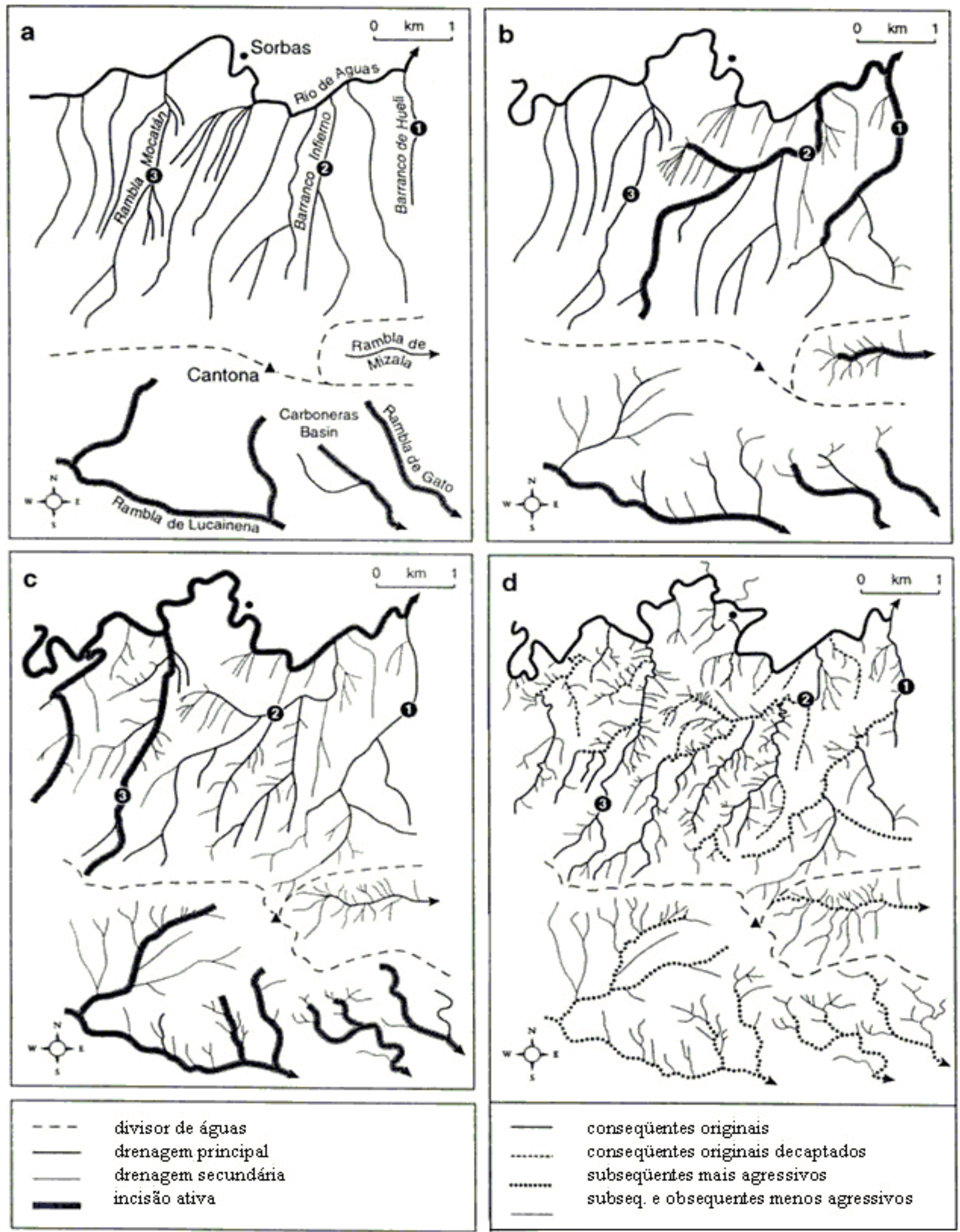

Figura 4 Captura fluvial por aplanamento lateral (Espanha). (a) Situação pré-captura (Pleistoceno médio) (b) Drenagem imediatamente após a captura (Pleistoceno/Holoceno) (c) Drenagem pós captura (Holoceno) (d) Drenagem atual.

Fonte: MATHER (2000) 


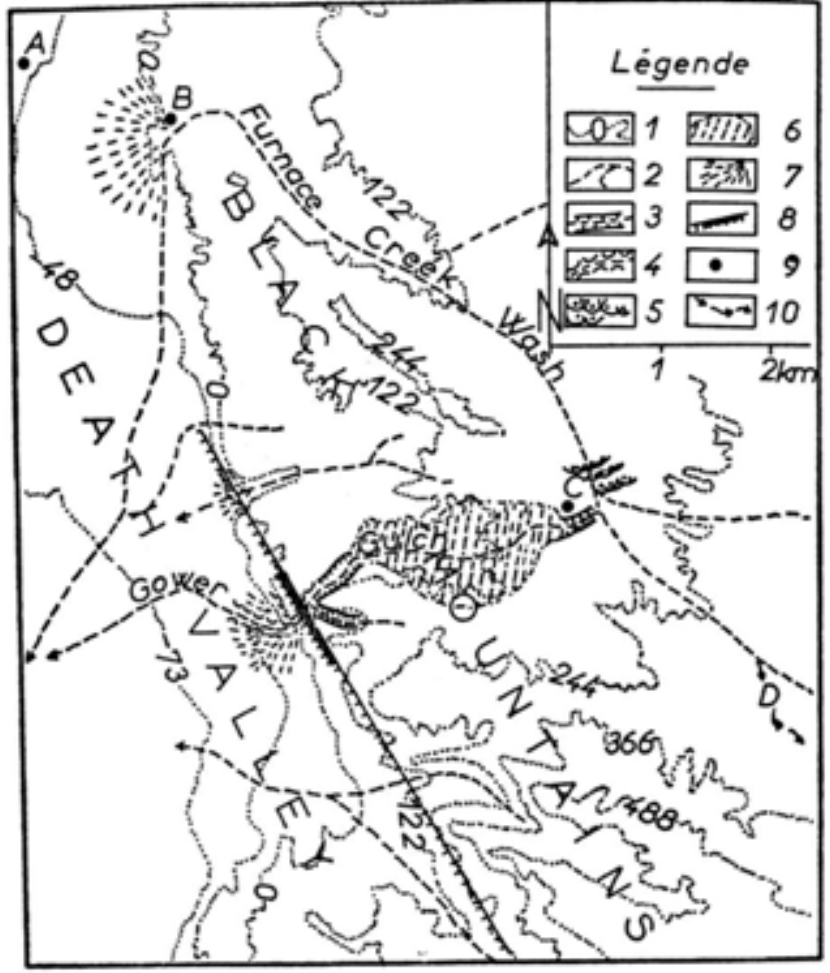

Figura 5 Captura fluvial por transbordamento (Estados Unidos) Fonte: POUQUET (1964)
Mapa da captura do Furnace Creek Wash

pelo Gower Gulch

1 - curvas de nivel

2 - rios

3 - gargantas estreitas

4 - encaixe do Gower Gulch no seu cone de dejeção

5 - barragem aluvial

6 - vales suspensos

7 - cones de dejeçẫo

8 - falha

9 - A) Furnace Creek Ranch

B) Furnace Creek Inn

C) Zabriskie Point

10 - Itinerário turístico

\section{Captura fluvial subterrânea}

Por erosão regressiva, um afluente do rio James, na Virgínia (E.U.A.) formou um túnel natural em rochas calcárias até alcançar outro rio que corria em direção oposta. 0 rio capturado passa no túnel, carregando todos os outros rios da sua bacia (Fig. 6). Neste túnel, houve o solapamento de seu teto, deixando como testemunhos pontes naturais e canyons (WOODWARD, 1936).

\section{Outros tipos de capturas fluviais}

O rio Sourou, na África Ocidental, que foi capturado pelo rio Volta Noire, dependendo da estação do ano, corre para o rio Volta Noire ao sul ou para o rio Níger ao norte (Fig. 7). Foram encontradas algumas evidências que provam a captura: a existência de um cotovelo de captura que separa o Volta superior do Volta médio; a direção alternativa do Sourou; a declividade do Sourou, que é menor do que do Volta Noire; uma ruptura de declive bem marcada no perfil do Volta, próximo à confluência com o Sourou; o contraste entre os cursos do Volta superior, que é um rio maduro e apresenta muitos meandros, o Sourou, que é um rio com baixa declividade e do Volta médio, que apresenta inúmeras barragens (HUBERT, 1912).
O rio Volta superior, com seu vale bem estabelecido, continuava pelo Sourou, enquanto o Volta médio, com seus afluentes conseqüentes originava-se na região acidentada de Daman-Yaco. A erosão remontante de seus afluentes, sobre os xistos, permitiu um deles atingir o vale Volta-Sourou e realizar a captura. Esta captura favoreceu grandemente o escoamento das águas do Volta superior pela criação de um novo nível de base, não somente muito inferior a este, que poderia se achar na foz do sistema Volta-Sourou, mas em uma época onde todo o trecho inferior desse sistema foi invadido pelos depósitos eólicos. É a partir desse momento que o Sourou pôs-se a correr alternadamente nos dois sentidos.

O estudo da captura do rio Sourou pelo Volta Noire foi resgatado mais tarde, na década de 30 do século passado. A possibilidade de ser restabelecido o fluxo do rio Sourou, tomado pela captura do Volta Noire, para irrigar uma região seca por vários meses durante 0 ano foi colocada em questão. Isto seria possivel pela construção de barragens cruzando o rio na junção com o Volta Noire, fechando-as de dezembro a julho, não permitindo que as águas do Sourou o atinjisse (FORBES, 1932). 

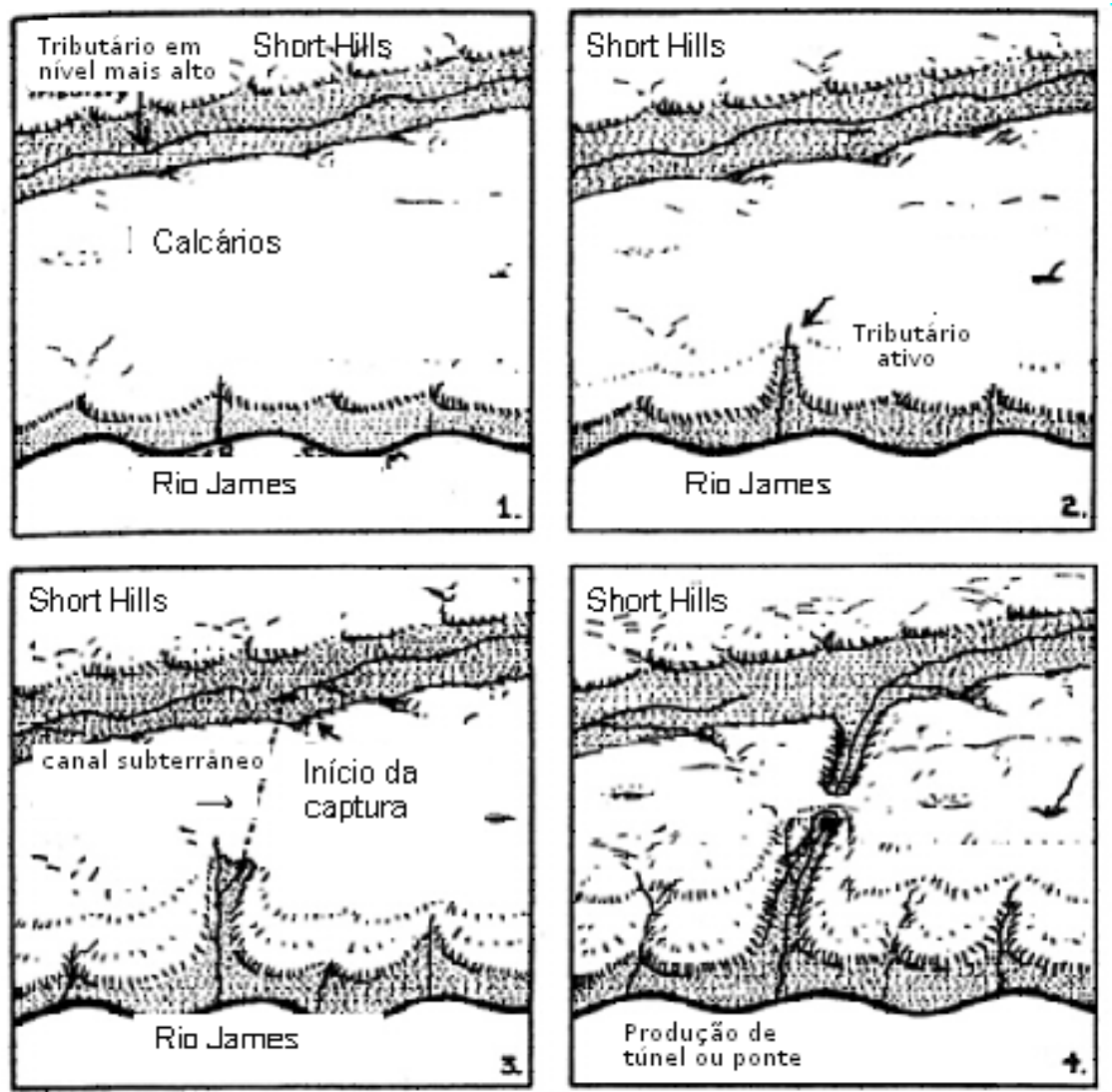

Figura 6 Captura fluvial subterrânea (EUA).

Fonte: WOODWARD (1936)

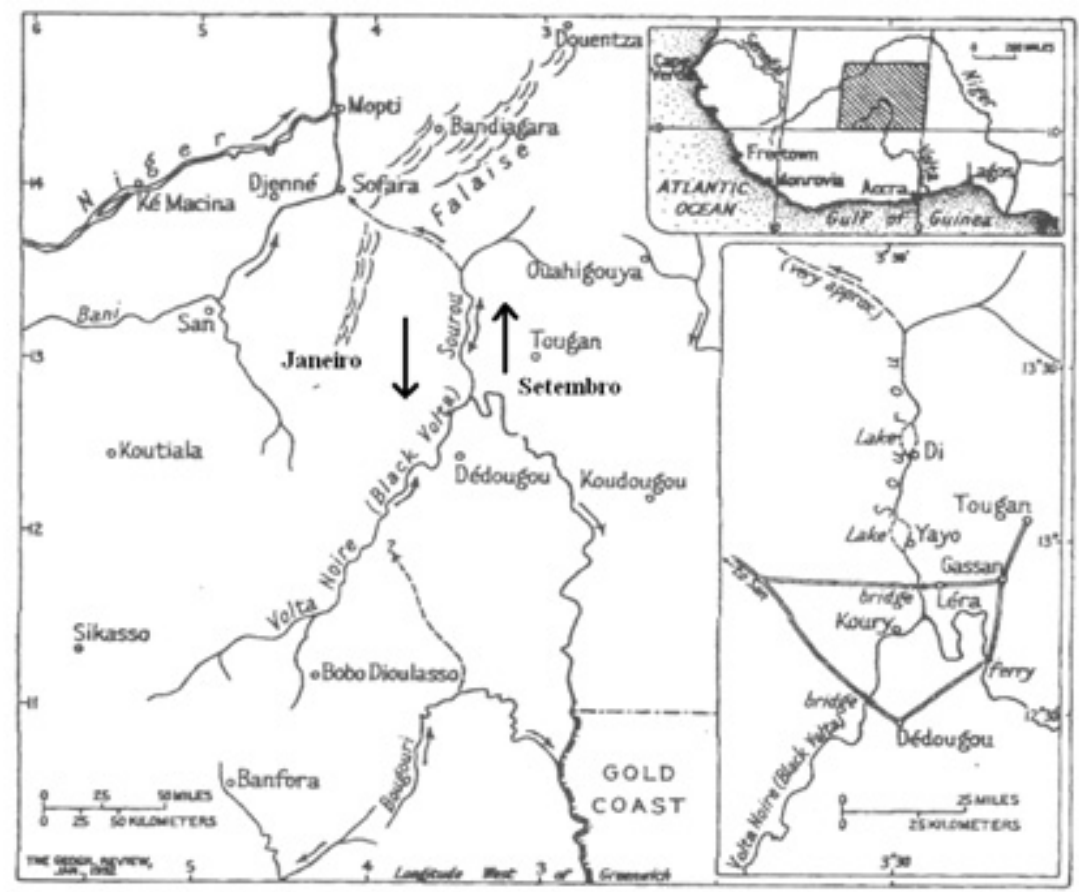

Figura 7 Drenagem na região do Volta-Sourou (África) Fonte: HUBERT (1912) 


\section{Capturas fluviais no Brasil}

No Brasil há ainda poucos pesquisadores envolvidos com 0 estudo das capturas fluviais. A maioria dos trabalhos existentes encontra-se incipientes ou pouco conclusivos. Alguns estudos de caso serão apresentados a seguir.

Um trabalho importante sobre capturas fluviais foi realizado em Guararema-SP, onde o cotovelo do rio Paraíba do Sul seria uma importante evidência de captura fluvial, pois este rio poderia ser um afluente do rio Tietê, antes da possível captura (Fig. 8).

Para AB'SABER (1957) é possível apenas apresentar o problema com base em especulações paleogeográficas, como 0 fizeram vários autores anteriores a ele, que relacionam a hipotética captura com os problemas de sedimentação pliocênica de ambas as bacias.

Enquanto o rio Paraíba do Sul ficou organizado por braços diversos, o Tietê continuou sua marcha para o oeste, superimpondose localmente à bacia sedimentar flúvio-lacustre, oriunda da barragem tectônica temporária na região de suas cabeceiras. 0 encaixamento do Paraíba, após a captura, foi da ordem de 350 $400 \mathrm{~m}$, enquanto o Tietê aprofundou seu leito muito menos, tendo sofrido interferências tectônicas que barraram sua saída para oeste e afundaram seu assoalho cristalino.

O que poderia negar a captura do Paraíba seria a ausência de sedimentos da bacia de Taubaté na bacia sedimentar de São Paulo. Isto poderia relacionar-se aos processos erosivos que ainda existem na região do Alto Tietê, quando as lagoas tectônicas da região do vale do Paraíba já constituíam massas d'água represadas tectonicamente. $\mathrm{O}$ que pode ter acontecido são diferenças de intensidade dos processos tectônicos nas duas bacias, com condições de escoamento diferentes, com obstrução completa e temporária no médio Paraíba e obstrução ligeira e moderada no alto Tietê (AB'SABER, 1957).

Atualmente sabe-se que no Neógeno, provavelmente no Mioceno, modificou-se o regime de esforços na área em questão, ocorrendo extensão NW-SE e compressão local NE-SW, relacionados a um binário transcorrente sinistral, orientado segundo a direção E-W. Nesta fase foram geradas as soleiras ou altos estruturais de Arujá e Queluz, entre outros. A transcorrência sinistral teria conduzido à formação da soleira de Arujá, alto que separa as bacias de São Paulo e Taubaté, pela tectônica transpressional ao longo das falhas NNW, soerguendo e erodindo os sedimentos e provocando a captura das cabeceiras do rio Tietê pelo rio Paraíba do Sul, com conseqüente mudança do nível de base e erosão na porção central da Bacia de Taubaté. O cotovelo do rio Paraíba do Sul seria conseqüência deste soerguimento (RICCOMINI et al., 1992; RICCOMINI e COIMBRA, 1992).

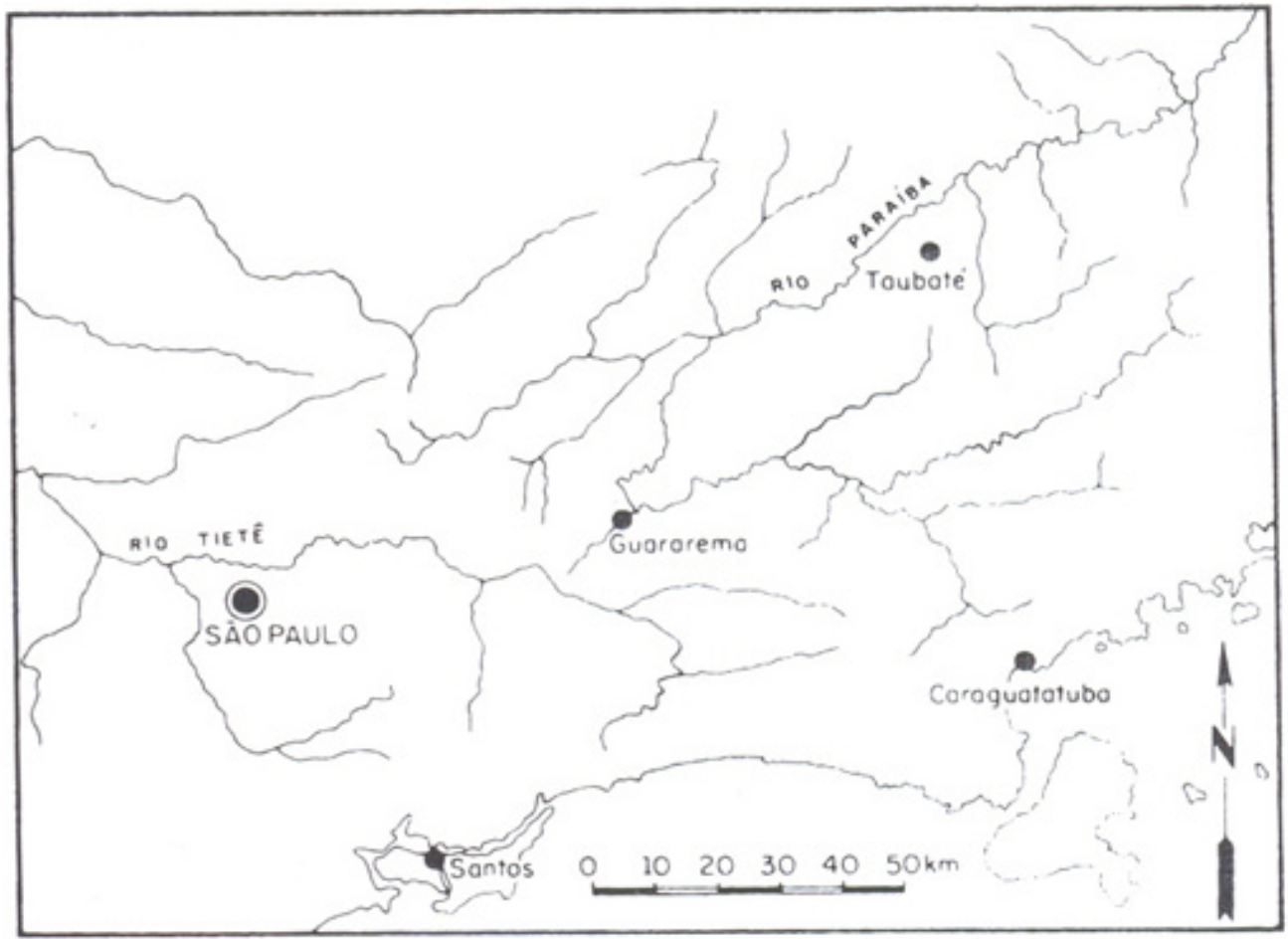

Figura 80 cotovelo do rio Paraíba do Sul na região de Guararema-SP Fonte: CHRISTOFOLETTI (1981) 
A captura fluvial do córrego Alegre pelo ribeirão Barreiro de Baixo no médio vale do Paraíba do Sul, associada à basculamento de blocos para NW e erosão remontante por decapitação deu-se por migração lateral do canal do rio Barreiro de Baixo. Esta captura foi responsável pela formação de soleiras escalonadas. No vale abandonado observou-se uma espessa colmatação coluvial e o desenvolvimento de uma vegetação mais densa, além de novas cabeceiras perpendiculares ao vale abandonado, cuja incisão expõe os sedimentos da antiga planície fluvial e dos terraços. Nesta área destacam-se também as capturas no trecho jusante do rio Sesmaria, do ribeirão Barreiro de Baixo e do rio Bananal, os quais, adaptados a lineamentos NE, mudam a direção de seus canais para $\mathrm{N}$ devido às reativações transcorrentes ao longo de lineamento E-W. $O$ vale que foi abandonado pelo rio Barreiro de Baixo é atualmente drenado pela porção jusante do rio Bananal e pelo seu afluente córrego do Cafundó (GONTIJO, 1999).

O Córrego São João drenava suas águas para o rio Paraíba do Sul e por captura fluvial foi abandonado, deixando um vale seco, morto ou abandonado. Foram evidenciados a mudança brusca de direção dos rios, a presença de seixos nos seus interflúvios, a presença de knickpoints a cerca de $300 \mathrm{~m}$ de altitude, próximos a cotovelos da drenagem, além de terraços fluviais à montante dos cotovelos nos canais. Concluiu-se que esta área está em fase de ajustes, ditadas por um novo nível de base regional (CASTANHEIRA et al., 2006).

Entre as serras da Bocaina e da Mantiqueira, abrangendo a bacia sedimentar de Resende, foram reconhecidos três sistemas de capturas fluviais, no médio vale do Paraíba do Sul, através da análise da rede de drenagem, na escala 1:50.000, associados a levantamentos estratigráficos e a dados estruturais. 0 primeiro e mais antigo sistema de capturas fluviais caracteriza-se por inflexões abruptas dos principais cursos fluviais para NW. $\mathrm{Na}$ posição dos interflúvios associados às inflexões fluviais encontramse preservados depósitos sedimentares terciários. Este sistema de capturas está relacionado a uma extensão NW-SE, ligada a um regime de transcorrência sinistral E-W de idade neogênica, representado pela forte inflexão do rio Barreiro de Baixo em seu médio-baixo curso, em direção à calha do rio Paraíba do Sul. O registro sedimentar do paleovale do rio Barreiro de Baixo corresponde a uma sucessão relativamente espessa de sedimentos terciários, afetados por falhas transtensionais de orientação NESW.

O segundo sistema de capturas fluviais caracteriza-se por inflexões, principalmente para SW e NE, de canais de baixa ordem hierárquica, afetando o traçado dos cursos fluviais maiores. É controlado por estruturas NW-SE associadas a um regime de transcorrência dextral E-W, datado do Pleistoceno final/Holoceno inicial, sendo melhor observado na borda norte da bacia sedimentar de Resende.

O terceiro sistema de capturas fluviais e mais recente caracteriza-se por inflexões de drenagem orientadas preferencialmente para SE e secundariamente para NW. $\mathrm{Na}$ posição de divisores associados às inflexões fluviais são observados depósitos aluviais holocênicos relacionados ao entulhamento sedimentar dos vales fluviais ocorrido no Holoceno inicial. Este sistema está associado à atuação de falhas normais transcorrentes de um regime extensional holocênico NW-SE no divisor entre os rios Barreiro de Baixo e Piracema (MELLO et al., 1999 a e b).

Foram realizados também estudos geomorfológicos e estruturais no frontão sudeste do Planalto de Campos do Jordão$\mathrm{SP}$, onde foram observadas capturas fluviais como resultado da superposição de regimes de esforços neotectônicos, como acontece no vale do rio Paraíba do Sul e na região do alto estrutural de Queluz. As falhas recentes desenvolveram-se por reativação tectônica ao longo das zonas de fraqueza pré-cambrianas, provocando capturas fluviais nas cabeceiras do ribeirão do Sino e córrego da Lavrinha, ao longo da Zona de Cisalhamento de Jundiuvira (HIRUMA et al., 2001; MODENESI-GAUTTIERI et al., 2002).

$\mathrm{Na}$ Serra do Mar, as evidências do caso da captura fluvial do alto rio Guaratuba, de acordo com o já citado trabalho realizado por OLIVEIRA (2003) e OLIVEIRA e QUEIROZ NETO (2007), foram confirmadas por uma evidência biológica encontrada na mesma área de estudo. Espécies de peixes encontradas no alto rio Guaratuba não foram encontradas no seu baixo curso, mas na bacia do alto Tietê, para onde o rio Guaratuba corria antes da sua captura (RIBEIRO et al., 2006).

A identificação de um processo de captura no Rio Grande do Sul foi feita pela análise da rede de drenagem regional em imagens orbitais Landsat, na escala 1:500.000 e por fotografias aéreas nas escalas 1:110.000 e 1:60.000, dirigida à pesquisa do processo de captura ocorrido nas cabeceiras de duas importantes bacias hidrográficas, a bacia do rio Jacuí (capturante) e a bacia do rio Camaquã (capturada). A análise da drenagem foi detalhada em fotografias aéreas na escala 1:60.000, onde $o$ traçado e análise da rede de drenagem revelou novas evidências do processo de captura, tais como o front regressivo de captura, o cotovelo de captura e padrão de drenagem barbed (ortogonal) na faixa de captura. Esta captura está associada à abertura da Depressão 
Periférica sul-rio-grandense e deu-se pelo consumo da superfície interplanáltica do Cerro da Cadeia e concomitante modelamento da superfície interplanáltica da Campanha, no Neógeno (LISBÔA e CASTRO, 1998).

Dados de elevação digital do terreno obtidos pela SRTM (SHUTTLE RADAR TOPOGRAPHIC MISSION) mostram sinais de um provável paleocurso do baixo rio Negro no Estado do Amazonas, representativo de um sistema de drenagem relicto, com fluxo geral para sul. Parte da rede hidrográfica atual, representada pelos rios Padauari e Carabinani, afluentes da margem direita do rio Negro, flui em sentido oposto, de SW para NE. Pelo seu traçado é possivel inferir que a confluência dos rios Negro e Solimões localizava-se onde hoje fica a desembocadura do rio Manacapuru, a cerca de $70 \mathrm{~km}$ a oeste da cidade de Manaus. A análise desta evidência, a partir de informações geológicas e geofísicas disponíveis sobre a Amazônia Central sugere que o traçado atual do rio Negro na região das Anavilhanas resultaria de uma megacaptura ativa na região (ALMEIDA FILHO et al., 2005).

\section{Considerações finais}

Os estudos sobre capturas fluviais tiveram grande interesse no final do século XIX, quando este fenômeno foi reconhecido na França por DAVIS (1896 a, be c, 1909). No início do século XX houve um menor interesse neste assunto, sendo retomado por alguns geomorfólogos na segunda metade deste mesmo século. Somente neste momento houve uma sistematização dos tipos de capturas fluviais, propondo-se que ela pode ocorrer através da absorção de um rio por outro, do recuo de uma das cabeceiras, do aplanamento lateral geral, do transbordamento de um rio, do desvio subterrâneo de um rio ou pela combinação destes tipos.

A captura fluvial é o resultado de eventos climáticos, geológicos e geomorfológicos e pode ocorrer em várias escalas de observação. A água é o acelerador da erosão e da captura fluvial, e esta pode ter algumas de suas evidências destruídas, tornando mais difícil a sua identificação. Como as linhas de drenagem estão preservadas durante e depois da captura, é possível traçar a sua evolução e a evolução do relevo onde ela está inserida. Sendo assim, as capturas fluviais são uma importante chave para o entendimento da evolução do relevo e, ainda hoje, são pouco estudadas por pesquisadores brasileiros e estrangeiros. 
OLIVEIRA, D (2010). River capture as relief evolution evidences: a review. Revista do Departamento de Geografia, n. 20, p. 37 - 50.

\begin{abstract}
This paper presents a review about river capture history based on literature and scientific articles, rescuing several authors that were involved to the subject. River capture (or stream piracy) is the natural diversion of waters from a river basin to another, promoting the expansion of drainage in relation to the neighboring basin. Nowadays, most of authors seems to agree that this geomorphological process can occur by subtraction of a river by another, by head ward erosion, by general lateral planation, by river overflow over another, or by subterranean diversion of a river up to reach its neighboring. At the point of capture, the captured stream shows sharp change of its direction, known as elbow of capture. The captor river is named diverter or predatory stream and the upstream river is named captured part. River capture shows important evidences of relief evolution, as the presence of an elbow of capture, dry, died or abandoned valleys with pebbles over it, and knickpoints over the river profile.
\end{abstract}

Keywords: River capture; Stream piracy; Relief evolution; River capture's evidences.

Recebido em 05 de março de 2007, aceito em 26 de agosto de 2008.

\section{Referências}

AB'SABER, A. N. (1957) O problema das conexões antigas e da separação da drenagem do Paraíba e do Tietê. Geomorfologia 26. São Paulo, Instituto de Geografia da USP, p. 38-49.

ALMEIDA FILHO, R.; MIRANDA, F. P. de \& BEISL, C. H. (2005) Evidência de uma mega captura fluvial no Rio Negro (Amazônia) revelada em modelo de elevação digital da SRTM. Anais do XII Simpósio Brasileiro de Sensoriamento Remoto, Goiânia, INPE, p. 1701-1707.

BAULIG, H. (1937) Captures fluviales et déversements. Mélanges de Géographie et d'Orientalisme.Tours, Arrault et Cie., p. 24-33.

BAULIG, H. (1950) Captures fluviales et déversements. Essais de Géomorphologie. Paris, Societé d'Édition: Les Belles Lettres, p. 114-124.

BISHOP, P. (1995) Drainage rearrangement by river capture, beheading and diversion. Progress in Physical Geography19, 4, p. 449-473.

CASTANHEIRA, M. V. S.; FREITAS, M. M. \& SARTI, T. P. (2006) Evolução da rede de drenagem controlada por nível de base regional e evidências do processo de captura fluvial no médio vale do rio Paraíba do Sul. VI Simpósio Nacional de Geomorfologia/ Regional Conference on Geomorphology, p. 1-10.
CHRISTOFOLETTI, A. (1975) Capturas fluviais. Enciclopédia Mirador Internacional. São Paulo, vol. 5, p. 2.049-2.051.

CHRISTOFOLETTI, A. (1977) Considerações sobre o nível de base, rupturas de declive, capturas fluviais e morfogênese do perfil longitudinal. Geografia, 2 (4), p. 81-102.

CHRISTOFOLETTI, A. (1981) Geomorfologia fluvial. Vol I-O canal fluvial. São Paulo, Ed. Edgard Blücher Ltda., 313p.

CLARK, G. M. (1989) Central and southern Appalachian water and wind gap origins: review and new data. Geomorphology, Amsterdam, 2, p. 209-232.

CROSBY, I. B. (1937) Methods of stream piracy. Journal of Geology, vol. XLV, n 5, p. 465-486.

DAVIS, W. M. (1896) La Seine, la Meuse et la Moselle. Annales de Géographie. Paris, Armand Colin et Cie, Editeurs, Tomo V, p. 25-49.

DAVIS, W. M. (1896) The Seine, the Meuse and the Moselle. National Geographic Magazine, Vol VII, nº 6, p-189-202.

DAVIS, W. M. (1896) The Seine, the Meuse and the Moselle. National Geographic Magazine, Vol VII, nº 7, p-228-237.

DAVIS, W. M. (1909) The Seine, the Meuse and the Moselle. Geographical Essays, Dover Publications, INC, p. 587-616.

FAIRBRIDGE, R. W. (1968) Stream capture, piracy. The Encyclopedia of Geomorphology. New York: Reinhold Book Corporation, p. 1054-1057.

FORBES,R. H. (1932) The desiccation problem in West África: 
The capture of the Sourou by the Black Volta. Geographical Review. Vol. 22, p. 97-106.

GILBERT, G.K. (1880) Report on the geology of the Henry Mountains. Washington, U.S. Geographical and Geological Survey of the Rocky Mountain Region.

GONTIJO, A. H. F. (1999) Morfometria do Médio Vale do Rio Paraíba do Sul: região da Serra da Bocaina, Estados de São Paulo e Rio de Janeiro. 259f. Tese (Doutorado) Instituto de Geociências e Ciências Exatas - Universidade Estadual Paulista, Rio Claro.

HIRUMA, S. T.; RICCOMINI, C. \& MODENESI-GAUTTIERI, M. C. (2001) Neotectônica no Planalto de Campos do Jordão, SP. In: Revista Brasileira de Geociências, 31 (3), p. 375-384.

HUBERT, H. (1912) Sur un important phénomène de capture dans I'Afrique Occidentale. Annales de Géographie. Vol. 21, p. 251-262.

LISBÔA, N. A. \& CASTRO, J. H. W. (1998) Captura do sistema fluvial Camaquã pelo sistema fluvial Jacuí-São Gabriel, RS. Anais do IX Simpósio Brasileiro de Sensoriamento Remoto, Santos, INPE, p. 415-424.

LOSSON, B. \& QUINIF, Y. (2001) La capture de la Moselle. Nouvelles données chronologiques par datations U/Th sur spéléothèmes. Karstologia, $n^{0} 37,1$, p. 29-40.

LOSSON, B. \& QUINIF, Y. (2004) The Moselle piracy: new chronological data from U/Th dating of speleothems. Speleogenesis and Evolution of Karst Aquifers. The Virtual Scientific Journal, 2 (1), p. 1-16.

MATHER, A. E. (2000) Adjustment of a drainage network to capture induced base-level change: un example from the Sorbas Basin, SE Spain. Geomorphology, Vol. 34, 3-4, p. 271-289.

MELLO, C. L.; METELO, C. M. S. RODRIGUES, L. F. \& CARMO I. O. (1999) Controles neotectônicos na evolução de sistemas de capturas fluviais no médio vale do rio Paraíba do Sul. VI Simpósio de Geologia do Sudeste, São Pedro, SBG/UNESP, p. 85.

MELLO, C. L.; METELO, C. M. S. RODRIGUES, L. F. \& CARMO I. O. (1999) Neotectonic influence on river capture systems in the Paraiba do Sul river middle valley (southeastern Brazil). IAG 1999 Regional Conference on Geomorphology. MILLER, A. M. (1915) Wind Gaps. Science. Vol. XLII, nº 1.086, p. 571-573.

MODENESI-GAUTTIERI, M. C.; HIRUMA, S. T. \& RICCOMINI, C. (2002) Morphotectonics of a high plateau on the northwestern flank of the Continental Rift of southeastern Brazil. Geomorphology, 43, p. 257-271.

OLIVEIRA, D. de (2003) A captura do Alto Rio Guaratuba: uma proposta metodológica para o estudo da evolução do relevo na Serra do Mar, Boracéia-SP. 105f.+anexos. Tese (Doutorado) - Departamento de Geografia-FFLCH-USP, São Paulo.

OLIVEIRA, D. de \& QUEIROZ NETO, J. P. (2007) Estudo da evolução do relevo na Serra do Mar no Estado de São Paulo a partir de um caso de captura fluvial. In: Geousp, São Paulo, 22, p. 73-88.

PEDERSON, D. T. (2001) Stream piracy revisited: a grounwatersapping solution. GSA TODAY, p. 4-10.

POUQUET, M. J. (1964) La capture du Furnace Creek Wash par le Gower Gulch (Vallée de la Mort, Californie). Bulletin de I'Association de Géographes Français. $n^{0} 322-323$, p. 43-51.

RIBEIRO, A. C.; LIMA, F. C. T. RICCOMINI, C. \& MENEZES, N. A. (2006) Fishes oh the Atlantic Rainforest of Boracéia: testimonies of the Quaternary fault reactivation within a Neoproterozoic tectonic province in Southeastern Brazil. Ichthyol. Explor. Freshwaters, vol. 17, nº 2, p. 157-164.

RICCOMINI, C.; COIMBRA, A. M. (1992) Geologia da Bacia Sedimentar de São Paulo. In: Negro Jr., A.; Ferreira, A.A.; Alonso, U.R.; Luz, P.A.C. (Org.). Solos da Cidade de São Paulo. São Paulo, Associação Brasileira de Mecânica dos Solos e Associação Brasileira de Engenharia de Fundações, p. 37-94.

RICCOMINI, C.; COIMBRA, A. M. \& TAKIYA, H. (1992) Tectônica e sedimentação na Bacia de São Paulo. ABAS; ABGE; SBGSP. (Org.). Problemas geológicos e geotécnicos na Região Metropolitana de São Paulo. São Paulo, Acqua, p. 21-45.

RITTER, D. F. (1972) The significance of stream capture in the evolution of a piedmont region, southern Montana. BerlinStuttgart, Z. Geomorph. N. F. 16 (1), p. 83-92.

SCHUMM, S. A. (1977) The fluvial system. New York, John Wiley \& Sons, $338 \mathrm{p}$.

SMALL, R.J. (1977) The study of lanforms. Cambridge: Cambridge University Press, 486p.

SUMMERFIELD, M. A. (1991) River capture. Global geomorphology. An introduction to the study of landforms. New York, p. 410-411.

TECHER, P. (1995) Etude morphologique et petrographique du complexe alluvial de moyenne terrasse sur le site de 
capture de la Moselle. 113f. Mémoire de maîtrise-Université de Nancy II.

THORNBURY, W. D. (1957) Principles of Geomorphology. New York, John Wiley \& Sons, Inc., 618p.

WOODRUFF, C. M. JR. (1977) Stream piracy near the Balcones Fault Zone, Central Texas. Journal of Geology, vol. 85, p. $483-490$.
WOODWARD, H. P. (1936) Natural bridge and natural tunnel, Virginia. Journal of Geology. Vol. 44, p. 604-616.

ZAPROWSKI, B. J.; EVENSON, E. B. \& EPSTEIN, J. B. (2002) Stream piracy in the Black Hills: a geomorphology lab exercise. Journal of Geoscience Education, vol. 50, p. 380-388. 